\title{
Glucuronidase Inhibitor
}

National Cancer Institute

\section{Source}

National Cancer Institute. Glucuronidase Inhibitor. NCI Thesaurus. Code C1017.

Any substance that inhibits glucuronidase, an enzyme involved in the hydrolysis of glucuronic acid from glucuronides. One of the key processes by which the human body eliminates toxic chemicals and hormones is by glucuronidation. When beta-glucuronidase deconjug ates these glucuronides, it prolongs the stay of the hormone or toxic chemical in the body. Inhibition of glucuronidase can produce chemoprotective effects. 